\title{
Erratum to: Thoracic and cardiovascular surgery in Japan during 2004
}

\author{
Annual Report by the Japanese Association for Thoracic Surgery
}

\author{
Committee for Scientific Affairs ${ }^{1}$. Teruhisa Kazui $^{2}$ • Hiroaki Osada ${ }^{3}$. \\ Hiromasa Fujita ${ }^{4}$
}

Published online: 26 October 2016

(C) The Japanese Association for Thoracic Surgery 2016

\section{Erratum to: Gen Thorac Cardiovasc Surg (2006) DOI 10.1007/s11748-006-0008-x}

In Table 5 in section (A) Caridovascular surgery, under the main column headings "Heart-lung assist," "Results," "Weaned," the final column heading, "Transplant," should have been "Survived."

The original publication of the article cited above included incorrect values in the following parts: in section (A) Cardiovascular surgery, Table 3 "Thoracic aortic aneurysm", both (1) Dissection and (2) Non-dissection, values in "9. Stent graft*a"; and in section (B) General thoracic surgery (Respiratory surgery), Table 1 "Total entry cases of general thoracic surgery". The corrected versions are below.

In Table 2 of section (A) Cardiovascular surgery, the table title "Acquired (total, $(1)+(2)+(4)+(5)+(6)$ $+(7)+$ isolated operation for arrhythmia in (3); 34,624" should be "Acquired (total, (1) + (2) + (4) + (5) + (6) $+(7)+$ isolated operation for arrhythmia in (3); 35,122", "(2) Ischemic heart disease (total, (A) + (B) + (C); 20,753)" should be "(2) Ischemic heart disease (total, (A) $+(\mathrm{B})+(\mathrm{C}) ; 21,251)$ ", and "(B) Operation for complications of MI (total; 823)" should be "(B) Operation for complications of MI (total; 1,321)".
The online version of the original article can be found under doi:10.1007/s11748-006-0008-x.

Committee for Scientific Affairs

survey-adm@umin.net

Tokyo, Japan

2 First Department of Surgery, Hamamatsu University School of Medicine, Hamamatsu, Japan

3 Department of Surgery, Division of Chest Surgery, St. Marianna University School of Medicine, Kawasaki, Japan

4 Department of Surgery, Kurume University School of Medicine, Kurume, Fukuoka, Japan 


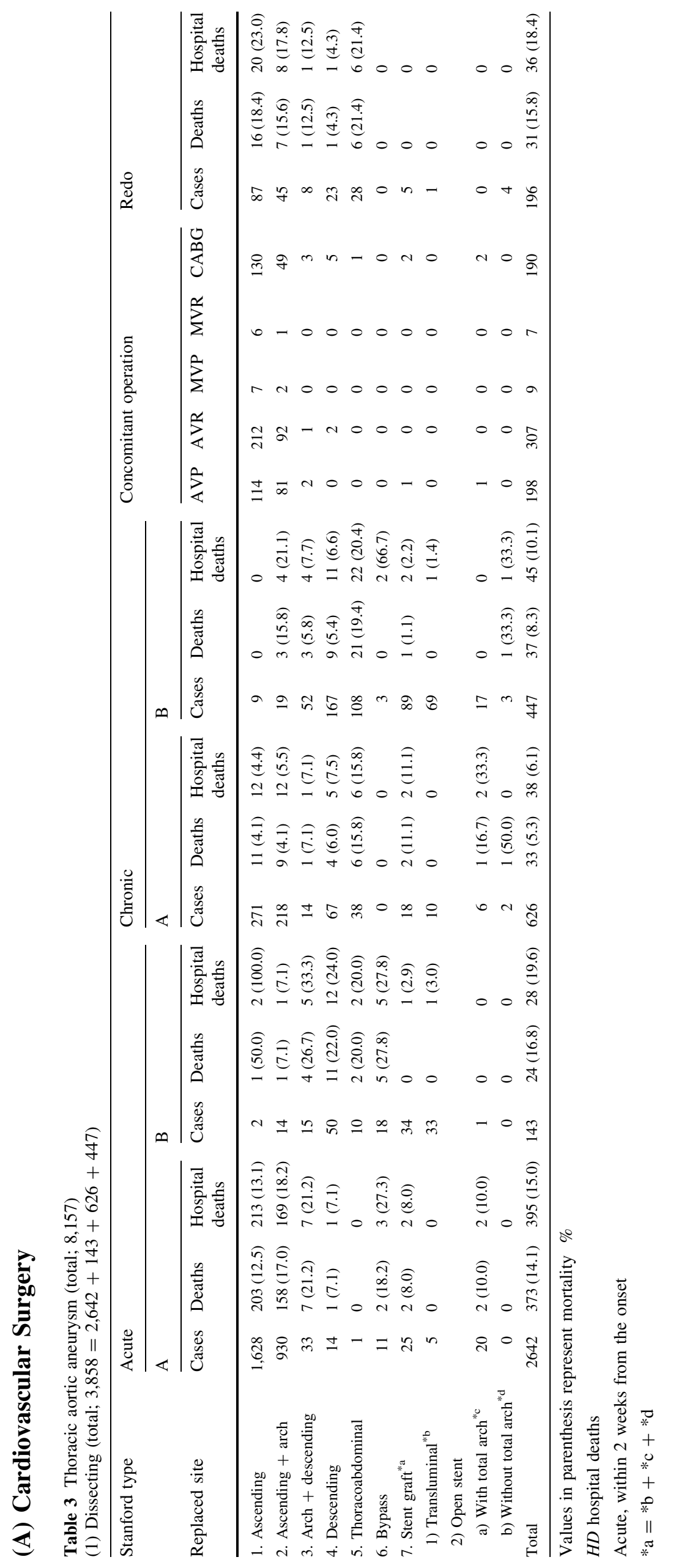




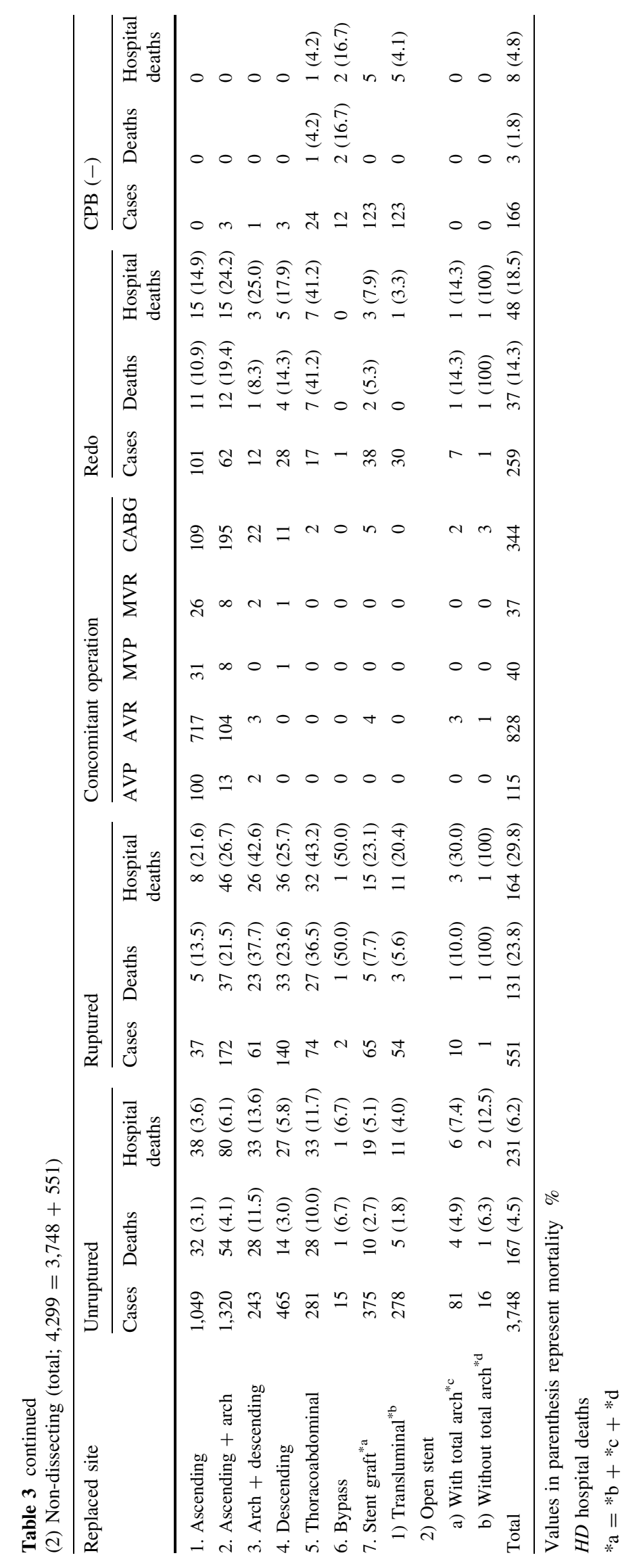




\section{(B) General Thoracic Surgery}

Table 1 Total entry cases of general thoracic surgery during 2004

\begin{tabular}{lrr}
\hline & Cases & \multicolumn{1}{c}{$\%$} \\
\hline Benign pulmonary tumor & 1,003 & 2.0 \\
Non-neoplastic benign disease & 1,612 & 3.3 \\
Primary lung cancer & 22,229 & 45.3 \\
Other primary malignant pulmonary tumor & 384 & 0.8 \\
Metastatic pulmonary tumor & 3,985 & 8.1 \\
Tracheal tumor & 66 & 0.1 \\
Mesothelioma & 247 & 0.5 \\
Chest wall tumor & 625 & 1.3 \\
Mediastinal tumor & 3,149 & 6.4 \\
Thymectomy without thymoma for MG & 325 & 0.7 \\
Inflammatory pulmonary disease & 2,009 & 4.1 \\
Empyema & 1,170 & 2.4 \\
Bullous disease excluding pneumothorax & 698 & 1.4 \\
Pneumothorax & 10,047 & 20.5 \\
Chest wall deformity & 311 & 0.6 \\
Diaphragmatic hernia including traumatic & 153 & 0.3 \\
Chest trauma excluding diaphragmatic hernia & 362 & 0.7 \\
Lung transplantation & 15 & 0.0 \\
Others & 637 & 1.3 \\
Total & 49,027 & 100.0 \\
\hline
\end{tabular}

